Research Article

Evolutionary Genetics

\title{
Rabies virus diversification in aerial and terrestrial mammals
}

Rafael N. Oliveira ${ }^{1}$ (D), Caio C. Freire ${ }^{2}$, Atila Iamarino ${ }^{2}$, Paolo M. Zanotto ${ }^{2}$, Rodrigo Pessoa ${ }^{3}$, Sabri S. Sanabani $^{3}$, Sibele Pinheiro de Souza ${ }^{4}$, Juliana G. Castilho ${ }^{1}$, Helena B. C. R. Batista ${ }^{1}$, Pedro Carnieli Jr. , Carla I. Macedo ${ }^{1}$, Jaqueline T. Watanabe ${ }^{3}$ and Paulo E. Brandão ${ }^{5}$ iD

${ }^{1}$ Instituto Pasteur, Laboratório de Biologia Molecular, São Paulo, SP, Brazil.

${ }^{2}$ Universidade de São Paulo, Instituto de Ciências Biomédicas (ICB-II), Departamento de Microbiologia, Laboratório de Evolução Molecular e Bioinformática, São Paulo, SP, Brazil.

${ }^{3}$ Universidade de São Paulo, Instituto de Medicina Tropical de São Paulo, Departamento de Virologia, São Paulo, SP, Brazil.

${ }^{4}$ Dechra Brasil, Londrina, PR, Brazil.

${ }^{5}$ Universidade de São Paulo, Faculdade de Medicina Veterinária e Zootecnica, Departamento de Medicina Veterinária Preventiva e Saúde Animal, São Paulo, SP, Brazil.

\begin{abstract}
Rabies is a fatal zoonotic infection of the central nervous system of mammals and has been known to humans for millennia. The etiological agent, is a neurotropic RNA virus in the order Mononegavirales, family Rhabdoviridae, genus Lyssavirus. There are currently accepted to be two cycles for rabies transmission: the urban cycle and the sylvatic cycle. The fact that both cycles originated from a common RABV or lyssavirus ancestor and the adaptive divergence that occurred since then as this ancestor virus adapted to a wide range of fitness landscapes represented by reservoir species in the orders Carnivora and Chiroptera led to the emergence of the diverse RABV lineages currently found in the sylvatic and urban cycles. Here we study full genome phylogenies and the time to the most recent common ancestor (TMRCA) of the RABVs in the sylvatic and urban cycles. Results show that there were differences between the nucleotide substitution rates per site per year for the same RABV genes maintained independently in the urban and sylvatic cycles. The results identify the most suitable gene for phylogenetic analysis, heterotachy among RABV genes and the TMRCA for the two cycles.
\end{abstract}

Keywords: Rabies virus, genome, molecular evolution, phylogeny, heterotachy.

Received: November 18, 2019; Accepted: June 17, 2020.

\section{Introduction}

Rabies is endemic throughout the world apart from the Antarctic, Australia, Japan and New Zealand. It is caused by Rabies lyssavirus - RABV (order Mononegavirales; family Rhabdoviridae; genus Lyssavirus; specie Rabies lyssavirus [http://www.ictvonline.org/virusTaxonomy.asp]), a negative-sense ssRNA virus maintained in independent epidemiologic cycles by specific genera and species, mainly in the orders Chiroptera and Carnivora (Rupprecht et al., 2002; Marston et al., 2012; Mollentze et al., 2014).

$\mathrm{RABV}$ is one of seventeen members of the genus Lyssavirus (King, A.M.K; Adans, M.J; Carstens, E.B; Lefkowitz 2012), fifteen of which have members of Chiroptera as exclusive reservoirs, showing the importance of this order as a reservoir for the genus (Rupprecht et al., 2017; Hu et al., 2018). This lends support to the hypothesis

Send correspondence to Rafael N. Oliveira. Instituto Pasteur, Laboratório de Biologia Molecular, Avenida Paulista, 393 CEP 01311000, São Paulo, SP, Brazil, email rafaeldenovaes@yahoo.com.br. that various existing RABV lineages had an RABV specific to bats as a common ancestor (Badrane and Tordo, 2001; Hayman et al., 2016; Velasco-Villa et al., 2017) and that this ancestral lineage differentiated into the various lineages in the urban and sylvatic cycles (Oliveira et al., 2010; Streicker et al., 2010, 2012a,b; Kuzmin et al., 2012). However, failure to isolate RABV or antibodies against this virus in bats in the Old World, particularly Asia, where the most ancient representatives of current RABV lineages are believed to be found, would appear to contradict this theory (Kuzmin and Rupprecht, 2007).

There are known to be two rabies transmission cycles: the urban cycle, in which the dog is the main reservoir and transmits the virus to other dogs, other domestic animals and man; and the sylvatic cycle, which is maintained by different terrestrial mammals and chiropterans (Acha and Szyfres, 2003).

Nevertheless, molecular evolution studies show that RABV differentiated into two major phylogenetic groupings (Badrane and Tordo, 2001; Bourhy et al., 2008; Kuzmin et 
al., 2012), which could be the basis for classification of rabies cycles into bat-related and dog-related cycles. The bat-related cycle (currently the sylvatic cycle) can be defined as all the RABV lineages maintained in different independent epidemiologic cycles exclusively in the Americas by wild animals, particularly chiropterans, while the dog-related cycle corresponds to all the lineages of rabies circulating in dogs (currently the urban cycle) and wild canids (currently the sylvatic cycle) maintained independently in multiple cycles around the world.

At least 35 RABV lineages have been described in the bat-related cycle, of which 31 are maintained in chiropterans. Of the four remaining lineages, two are maintained in skunks in Mexico and the south of the USA, one in racoons in the USA and one in the common marmoset (C. jacchus) in the northeast of Brazil. Eight major groups of genetic lineages are described in the dog-related cycle, for which the only reservoirs are members of the order Carnivora, particularly the domestic dog and wild canids (Bourhy et al., 2008; Kuzmin et al., 2012). Of these eight groups identified in the dog-related cycle, only the Africa 3 complex, for which the reservoir is the African yellow mongoose, is not maintained in dogs.

In view of the limited number of complete RABV genomes published, the uncertainty surrounding the classification of rabies transmission cycles and the lack of robust evolutionary analyses for RABV, our objective in this study was to generate data and understand the various divergence events for RABV isolated from terrestrial mammals and bats based on estimates of phylogeny, evolution rates and time to the most recent common ancestor (TMRCA) using complete genome sequences.

\section{Material and Methods}

\section{RABV strains}

Twenty-one RABV strains from different Brazilian rabies reservoirs (Table 1) isolated on the first passage in mouse brains, according to Koprowski (1996), were used for full genome sequencing. These isolates were obtained from vampire bats (Desmodus rotundus) and insectivorous bats (Eptesicus furinalis, Myotis nigricans, Nyctinomops laticaudatus and Tadarida brasiliensis), crab-eating foxes (Cerdocyon thous), dogs, cattles and marmosets (Callithrix jacchus), send to the virology laboratory of the Instituto Pasteur (São Paulo/Brazil) for rabies surveillance from 2006 to 2012.

These strains were classified in the RABV lineages Myotis I, Eptesicus I, Eptesicus II, Nyctinomops, Tadarida brasiliensis South America, Desmodus rotundus, Cerdo-

Table 1 - Temperature cycles used in PCR to amplify the RABV genome.

\begin{tabular}{lcc}
\hline Cycle & Temperature & Time \\
\hline $1 \mathrm{X}$ & $94^{\circ} \mathrm{C}$ Denaturation & 5 minutes \\
$35 \mathrm{X}$ & $94^{\circ} \mathrm{C}$ Denaturation & 45 seconds \\
$55^{\circ} \mathrm{C}$ Annealing & 45 seconds \\
$68^{\circ} \mathrm{C}$ Extension & 12 minutes \\
$68^{\circ} \mathrm{C}$ Extension & 10 minutes \\
\hline
\end{tabular}

cyon thous and Callithrix jacchus based on partial N or G gene sequences as previously described (Favoretto et al., 2001; Carnieli et al., 2008; Oliveira et al., 2010; Almeida et al., 2011).

This work complies with Protocol n ${ }^{\circ}$ 2030/2010 issued by the "Ethics Committee in the use of animals" of the School of Veterinary Medicine and Animal Science of University of São Paulo.

\section{Full-genome RT-PCR}

Total viral RNA was extracted from infected mouse brain with TRIzol TM (Life Technologies, Carlsbad, CA, USA) according to the manufacturer's instructions.

The double-stranded genome-length cDNA (genomic reverse transcription) was synthesized using the antisense primer "Final" (Campos et al., 2011) targeting the 3'UTR 21 first nucleotides of trailer region of the antigenomic RNA (nucleotides 11904-11924 Rabies virus M13215.1 GenBank accession number) and RevertAid Premium Reverse Transcriptase (Fermentas ) (Oliveira, 2014).

For each sample, $15 \mu \mathrm{L}$ of the extracted RNA was added to the mix for reverse transcription containing $8 \mu \mathrm{L}$ $5 \mathrm{X}$ RT Buffer, $6 \mu \mathrm{L}$ of the dNTP pool at $10 \mathrm{mM}, 5 \mu \mathrm{L}$ of the "Final" antisense primer at $10 \mu \mathrm{M}, 400 \mathrm{U}$ of Reverse Transcriptase enzyme RevertAid Premium Reverse Transcriptase (Fermentas ), $1 \mu \mathrm{L}$ of RNAsin (Invitrogen ) and $35 \mu \mathrm{L}$ of ultra-pure DNAse/RNAse free water to a final volume of 50 $\mu \mathrm{L}$, carrying out reverse transcription at $42{ }^{\circ} \mathrm{C} / 180$ minutes followed by a $70{ }^{\circ} \mathrm{C} / 15$ minute reverse transcriptase inactivation cycle.

Genomic RABV amplicons (circa $12 \mathrm{~kb}$ ) were obtained by PCR using a pair of primers targeting the leader and trailer regions of the RABV genome (Campos et al., 2011), $1 \mu \mathrm{L}$ of genomic cDNA and GoTaq ${ }^{\mathrm{TM}}$ Long PCR Master Mix 2X (Promega) according to the manufacturer's instructions (Oliveira 2014).

The PCR protocol for the amplification of the complete RABV genome consisted of: $25 \mu \mathrm{L}$ of GoTaq ${ }^{\circledR}$ Long PCR Master Mix 2X (Promega), $1 \mu \mathrm{L}$ of the "Início" (sense) and "Final" (antisense) primers at a concentration of $10 \mu \mathrm{M}$, $1 \mu \mathrm{L}$ of c-DNA and $22 \mu \mathrm{L}$ of ultra-pure DNAse/RNAse free water to a final volume of $50 \mu \mathrm{L}$ and taken to the thermocycler and subjected to the cycle described in Table 1 .

\section{Whole viral genome library preparation and full-genome sequencing}

Purified products were quantitated using Quant-IT HS reagents (Invitrogen, Life Technologies, Carlsbad, CA), and approximately $1 \mathrm{ng}$ of each was used in a fragmentation reaction mix using a Nextera XT DNA sample prep kit according to the manufacturer's protocol. Briefly, tagmentation and fragmentation of each product were simultaneously performed by incubation for $5 \mathrm{~min}$ at $55^{\circ} \mathrm{C}$ followed by incubation in neutralizing tagment buffer for $5 \mathrm{~min}$ at room temperature. After neutralization of the fragmented DNA, a light 12-cycle PCR was performed with Illumina Ready Mix to 
add Illumina flowcell adaptors, indexes and common adapters for subsequent cluster generation and sequencing. Amplified DNA was then purified using Agencourt AMPure XP beads (Beckman Coulter), which excluded very short library fragments. Following AMPure purification, the quantity of each library was normalized to ensure equally library representation in our pooled samples. Prior to cluster generation, normalized libraries were further quantified by qPCR using the SYBR fast Illumina library quantification kit (KAPA Biosystems) following the instructions of the manufacturer. The qPCR was run on the 7500 Fast Real-Time PCR System (Applied Biosystems). The thermocycling conditions consisted of an initial denaturation step at $95{ }^{\circ} \mathrm{C}$ for $5 \mathrm{~min}$ followed by 35 cycles of $\left[30 \mathrm{~s}\right.$ at $95^{\circ} \mathrm{C}$ and $45 \mathrm{~s}$ at $60{ }^{\circ} \mathrm{C}$ ]. The final libraries were pooled at equimolar concentration and diluted to $4 \mathrm{nM}$. To denature the indexed DNA, $5 \mu \mathrm{L}$ of the 4 nM library were mixed with $5 \mu \mathrm{L}$ of $0.2 \mathrm{~N}$ fresh $\mathrm{NaOH}$ and incubated for $5 \mathrm{~min}$ at room temperature. $990 \mu \mathrm{L}$ of chilled Illumina HT1 buffer was added to the denatured DNA and mixed to make a $20 \mathrm{pM}$ library. After this step, $360 \mu \mathrm{L}$ of the $20 \mathrm{pM}$ library was multiplexed with $6 \mu \mathrm{L}$ of $12.5 \mathrm{pM}$ denatured PhiX control to increase sequence diversity and then mixed with $234 \mu \mathrm{L}$ of chilled HT1 buffer to make a $12 \mathrm{pM}$ sequenceable library. Finally, $600 \mu \mathrm{L}$ of the prepared library was loaded on an Illumina MiSeq clamshell style cartridge for paired end 250 sequencing.

After they had been sequenced in an Illumina $\mathrm{MiSeq}^{\mathrm{TM}}$, the reads were assembled without the use of reference genomes (de novo assembly) in CLC Genomics Workbench 6 . When the assembled contigs in a genome were smaller than expected based on the size of the sequenced PCR fragment, they were extended by mapping the reads to the reference with $95 \%$ similarity and without gap opening or by using de novo assembly with the same similarity criterion in Geneious 6. Both the extended and the de novo assembled contigs had their reads mapped to the reference again and were evaluated in terms of their variability based on the number and quality of reads using the Quality-based Variant Detection function in CLC Genomics Workbench version 5.5.

Low-quality sequences were removed from the analysis, i.e., sequences with a phred Q score lower than 20, using at least 100 reads per site and applying a penalty for homopolymer regions (a quality reduction of $30 \%$ for every additional base). After editing, the regions of the RABV sequences corresponding to the Início and Final primers were removed.

\section{The dataset used for the analysis}

The dataset used consisted of 138 complete RABV genome sequences from GenBank and the RABV genome sequences obtained in this study (Table 2). The sequences from GenBank were extracted with a PERL script using the criterion that they should have more than 10,000 nucleotides and that information about year, country and original host should be available. In all, there were 159 sequences, corresponding to 100 in the bat-related RABV cycle and 59 in the dog-related cycle. The region used for the analysis extended from nucleotide 59 to nucleotide 11801 (in relation to the PV strain, accession number M13215.1), i.e., from the first nucleotide in the $\mathrm{N}$ gene messenger RNA to the stop codon in the $\mathrm{L}$ gene.

The only sequences used were those that did not show any evidence of recombination events when examined by the RDP, GenConv, Chimaera, MaxChi, Bootscan, SiScan and 3Seq methods implemented in RDP4 (beta 4.8 version) (Martin et al., 2010) with a 95\% confidence interval and Bonferroni correction for multiple comparisons.

\section{Phylogenetic signal analysis}

The phylogenetic signal content for the RABV genome and each RABV gene was investigated with the likelihood mapping algorithm (Strimmer and von Haeseler, 1997) implemented in TREE-PUZZLE v 5.2 (Schmidt et al., 2002), which quantifies the well-resolved phylogenetic quartets in the database.

\section{Heterotachy analysis}

Genome sequences were used in the heterotachy analysis with PAML v 4.6 (Yang, 2007) to test the following hypotheses: $H_{0}$ - the viral lineages in both RABV cycles are under the same molecular clock, and $H_{A}$ - the lineages in each cycle are under different clocks.

One hundred phylogenetic trees were constructed using the ML (maximum likelihood) method with GARLI v 2.0 (Bazinet et al., 2014), and the tree with the highest value ML was used.

To test the significance of the difference between the likelihood (L) values for each model studied, the likelihood ratio test (LRT) was used according to the equation next.

LRT $=2 \times(L 1-L 2)$ where L1 is equal to the likelihood of model 1 and L2 the likelihood of model 2. In this case, the degrees of freedom employed were equal to 157 , which is equivalent to the number of taxa $-2(\mathrm{~N}-2)$. The level of significance established was 0.05 , which critical value is 206.390, in a chi-square table.

When the hypothesis of different molecular clocks for the RABV genomes in the two cycles was confirmed, analyses were carried out for each cycle and for each gene to determine the genes or regions of the RABV genome responsible for this phenomenon so that they could then be removed from the joint analyses of the cycles.

\section{Estimates of the nucleotide substitution rate per site per year, estimates of the TMRCA and phylogeny estimates}

Estimates of the nucleotide substitution rates per site per year and the time to the most recent common ancestor (TMRCA) for genome sequences in which heterotachy was detected were initially made for each of the five genes for each cycle separately. After this analysis, only those genes with similar substitution rates in both cycles were used to estimate the TMRCA and carry out the phylogenetic analysis. 
Table 2 - Strains used in the study: accession number, reference, host, country and year of isolation.

\begin{tabular}{|c|c|c|c|c|}
\hline GenBank accession number & Strain & Host & Country & Year \\
\hline JQ685971.1 & AZ3003 & Antrozous pallidus & United States & 2009 \\
\hline AB699220.1 & BDR5 & Capra aegagrus hircus & Bangladesh & 2010 \\
\hline KM594025.1 & IP5402/07 & Callithrix jacchus & Brazil & 2007 \\
\hline KM594024.1 & IP1770/12 & Callithrix jacchus & Brazil & 2012 \\
\hline KM594023.1 & IP $6634 / 08$ & Callithrix jacchus & Brazil & 2008 \\
\hline JQ685973.1 & A111043 & Canis latrans & United States & 2011 \\
\hline JQ685917.1 & COCoyot 2010 & Canis latrans & United States & 2010 \\
\hline KC196743.1 & DRVNG11 & Canis lupus familiaris & Nigeria & 2011 \\
\hline HQ450385.1 & DRVAH08 & Canis lupus familiaris & China & 2008 \\
\hline JN609295.1 & FJDRV & Canis lupus familiaris & China & 2008 \\
\hline FJ712194.1 & D02 & Canis lupus familiaris & China & 2008 \\
\hline FJ712193.1 & D01 & Canis lupus familiaris & China & 2008 \\
\hline KC660078.1 & Fengtai & Canis lupus familiaris & China & 2012 \\
\hline FJ866836.1 & FJ009 & Canis lupus familiaris & China & 2008 \\
\hline FJ866835.1 & FJ008 & Canis lupus familiaris & China & 2008 \\
\hline GU345746.1 & CQ92 & Canis lupus familiaris & China & 1992 \\
\hline GU358653.1 & GX4 & Canis lupus familiaris & China & 1994 \\
\hline JQ730682.1 & CYN1009D & Canis lupus familiaris & China & 2010 \\
\hline EU293113.1 & 9001FRA & Canis lupus familiaris & French Guiana & 1990 \\
\hline KF154999.1 & RV2417 & Canis lupus familiaris & United Kingdom & 2008 \\
\hline KF154998.1 & RV2324 & Canis lupus familiaris & Israel & 1950 \\
\hline KM594039.1 & IP 7841/09 & Canis lupus familiaris & Brazil & 2009 \\
\hline AB517659.1 & BRdg335 & Canis lupus familiaris & Brazil & 2003 \\
\hline KF155002.1 & RV2772 & Canis lupus familiaris & Tanzania & 2010 \\
\hline JQ944706.1 & $1352 \mathrm{KRA}$ & Canis lupus familiaris & Russia & 2008 \\
\hline JQ944705.1 & 1350KRA & Canis lupus familiaris & Russia & 2008 \\
\hline AB206409.2 & BR_Pfx3 & Cerdocyon thous & Brazil & 2001 \\
\hline AB362483.1 & BR_Pfx1 & Cerdocyon thous & Brazil & 2002 \\
\hline KC169986.1 & GX'- & Bos taurus & China & 2009 \\
\hline KC193267.1 & CNM1101C & Bos taurus & China & 2011 \\
\hline JQ685936.1 & $3634 \mathrm{DR}$ & Bos taurus & Mexico & 2009 \\
\hline KM594043.1 & IP $4005 / 12$ & Bos taurus & Brazil & 2012 \\
\hline KF155001.1 & RV2627 & Bos taurus & Morocco & 2009 \\
\hline KF155000.1 & RV2516 & Bos taurus & Iraq & 2010 \\
\hline KC171643.1 & $08 \mathrm{~F} 40$ & Bos taurus & South Korea & 2008 \\
\hline KM594041.1 & IP 2990/13 & Desmodus rotundus & Brazil & 2013 \\
\hline KM594042.1 & IP 2991/13 & Desmodus rotundus & Brazil & 2013 \\
\hline KM594040.1 & IP 2992/13 & Desmodus rotundus & Brazil & 2013 \\
\hline JQ944707.1 & $1410 \mathrm{KOM}$ & Cervidae & Russia & 2008 \\
\hline JQ685942.1 & AZBAT65094 & Eptesicus fuscus & United States & 1981 \\
\hline JQ685931.1 & WA0173 & Eptesicus fuscus & United States & 2000 \\
\hline JQ685903.1 & CA04148 & Eptesicus fuscus & United States & 2004 \\
\hline JQ685961.1 & AZ10140 & Eptesicus fuscus & United States & 2010 \\
\hline JQ685950.1 & A093504 & Eptesicus fuscus & United States & 2009 \\
\hline JQ685897.1 & SM5442 & Eptesicus fuscus & United States & 2001 \\
\hline JQ685923.1 & SM4871 & Eptesicus fuscus & United States & 1999 \\
\hline JQ685926.1 & AZ2408 & Eptesicus fuscus & United States & 2005 \\
\hline JQ685960.1 & SM4872 & Eptesicus fuscus & United States & 2001 \\
\hline JQ685956.1 & AZBAT7453 & Eptesicus fuscus & United States & 1975 \\
\hline JQ685909.1 & CA100 & Eptesicus fuscus & United States & 2005 \\
\hline JQ685907.1 & SM3849 & Eptesicus fuscus & United States & 1996 \\
\hline JQ685913.1 & AZBAT6763 & Eptesicus fuscus & United States & 1985 \\
\hline JQ685974.1 & SM3844 & Eptesicus fuscus & United States & 1995 \\
\hline JQ685898.1 & A093500 & Eptesicus fuscus & United States & 2009 \\
\hline JQ685946.1 & SM4862 & Eptesicus fuscus & United States & 1999 \\
\hline JQ685951.1 & AZ10144 & Eptesicus fuscus & United States & 2010 \\
\hline JQ685920.1 & $\mathrm{EF}$ & Eptesicus fuscus & United States & 1984 \\
\hline
\end{tabular}


Table 2 (cont.)

\begin{tabular}{|c|c|c|c|c|}
\hline GenBank accession number & Strain & Host & Country & Year \\
\hline JQ685925.1 & WAEF03 & Eptesicus fuscus & United States & 2004 \\
\hline KM594028.1 & IP $346 / 10$ & Eptesicus furinalis & Brazil & 2010 \\
\hline KM594027.1 & IP 230/10 & Eptesicus furinalis & Brazil & 2010 \\
\hline KM594026.1 & IP 512/09 & Eptesicus furinalis & Brazil & 2009 \\
\hline KM594029.1 & IP $3208 / 06$ & Eptesicus furinalis & Brazil & 2006 \\
\hline JQ647510.1 & WH11 & Equidae & China & 2011 \\
\hline JQ423952.1 & BJ2011E & Equidae & China & 2011 \\
\hline JQ685945.1 & SM6709 & Felis silvestris catus & United States & 2005 \\
\hline KC595281.1 & RusLipetsk8053c & Felis silvestris catus & Russia & 2011 \\
\hline JQ685948.1 & OR05455 & Urocyon cinereoargenteus & United States & 2010 \\
\hline JQ685977.1 & OR58 & Urocyon cinereoargenteus & United States & 2010 \\
\hline JQ685924.1 & OR704 & Urocyon cinereoargenteus & United States & 2010 \\
\hline JQ685914.1 & OR703 & Urocyon cinereoargenteus & United States & 2010 \\
\hline JQ685933.1 & SM5950 & Urocyon cinereoargenteus & United States & 2004 \\
\hline JQ685934.1 & 2401 & Urocyon cinereoargenteus & United States & 2009 \\
\hline JQ685972.1 & 2395 & Urocyon cinereoargenteus & United States & 2009 \\
\hline JQ685939.1 & 2399 & Urocyon cinereoargenteus & United States & 2009 \\
\hline JQ685892.1 & 2398 & Urocyon cinereoargenteus & United States & 2009 \\
\hline JQ685908.1 & 1060 & Urocyon cinereoargenteus & United States & 2009 \\
\hline JQ685928.1 & 2403 & Urocyon cinereoargenteus & United States & 2009 \\
\hline JQ685896.1 & 2402 & Urocyon cinereoargenteus & United States & 2009 \\
\hline JQ685912.1 & 2400 & Urocyon cinereoargenteus & United States & 2009 \\
\hline JQ685957.1 & OR8767 & Urocyon cinereoargenteus & United States & 2009 \\
\hline JQ685918.1 & OR05506 & Urocyon cinereoargenteus & United States & 2010 \\
\hline EU293115.1 & 9147FRA & Vulpes $s p$ & France & 1991 \\
\hline JQ944708.1 & $1564 \mathrm{NNO}$ & Vulpes vulpes & Russia & 2008 \\
\hline KC595280.1 & RusLipetsk8052f & Vulpes vulpes & Russia & 2011 \\
\hline KC595283.1 & RusLipetsk8057f & Vulpes vulpes & Russia & 2011 \\
\hline KC595282.1 & RusLipetsk8054f & Vulpes vulpes & Russia & 2011 \\
\hline JQ685899.1 & A100515 & Urocyon cinereoargenteus & United States & 2009 \\
\hline JQ685943.1 & A100511 & Urocyon cinereoargenteus & United States & 2009 \\
\hline GU345747.1 & $\mathrm{J}$ & Homo sapiens & China & 1986 \\
\hline EU643590.1 & HN10 & Homo sapiens & China & 2006 \\
\hline EU293111.1 & 8764THA & Homo sapiens & Thailand & 1983 \\
\hline JQ685953.1 & $3645 \mathrm{DR}$ & Homo sapiens & Mexico & 2009 \\
\hline AB569299.1 & H081320 & Homo sapiens & Sri Lanka & 2008 \\
\hline KC737850.1 & A115300 & Homo sapiens & United States & 2011 \\
\hline KF154996.1 & RV61 & Homo sapiens & United Kingdom & 1987 \\
\hline JX473839.1 & 192J09 & Canis mesomelas & Namibia & 2009 \\
\hline JX473838.1 & $178 \mathrm{~J} 09$ & Canis mesomelas & Namibia & 2009 \\
\hline JQ685916.1 & FL1010 & Lasiurus intermedius & United States & 2002 \\
\hline JQ685915.1 & TX4904 & Lasiurus intermedius & United States & 2002 \\
\hline JQ685895.1 & WA1185 & Lasionycteris noctivagans & United States & 2003 \\
\hline JQ685902.1 & TN209 & Lasiurus borealis & United States & 2005 \\
\hline JQ685910.1 & TX5960 & Lasiurus xanthinus & United States & 2002 \\
\hline JQ685900.1 & FL769 & Lasiurus seminolus & United States & 2003 \\
\hline JQ685919.1 & NJ2262 & Lasiurus borealis & United States & 2005 \\
\hline JQ685947.1 & $\mathrm{TN} 310$ & Lasiurus cinereus & United States & 2004 \\
\hline JQ685921.1 & FL1078 & Myotis austroriparius & United States & 2001 \\
\hline JQ685927.1 & SM5080 & Mephitis mephitis & United States & 2001 \\
\hline JQ685893.1 & SM5079 & Mephitis mephitis & United States & 2001 \\
\hline JQ685932.1 & SM5076 & Mephitis mephitis & United States & 2001 \\
\hline JQ685949.1 & SM5075 & Mephitis mephitis & United States & 2001 \\
\hline JQ685966.1 & SM5470 & Mephitis mephitis & United States & 2001 \\
\hline JQ685935.1 & SM5074 & Mephitis mephitis & United States & 2001 \\
\hline JQ685906.1 & SM5102 & Mephitis mephitis & United States & 2001 \\
\hline JQ685958.1 & SM5101 & Mephitis mephitis & United States & 2001 \\
\hline
\end{tabular}


Table 2 (cont.)

\begin{tabular}{|c|c|c|c|c|}
\hline GenBank accession number & Strain & Host & Country & Year \\
\hline JQ685904.1 & SM5081 & Mephitis mephitis & United States & 2001 \\
\hline JQ685962.1 & SM5441 & Mephitis mephitis & United States & 2001 \\
\hline JQ685969.1 & SM5440 & Mephitis mephitis & United States & 2001 \\
\hline JQ685959.1 & SM5451 & Mephitis mephitis & United States & 2001 \\
\hline JQ685940.1 & SM5100 & Mephitis mephitis & United States & 2001 \\
\hline JQ685911.1 & SM5077 & Mephitis mephitis & United States & 2001 \\
\hline JQ685930.1 & SM5103 & Mephitis mephitis & United States & 2001 \\
\hline JQ685964.1 & SM5596 & Mephitis mephitis & United States & 2004 \\
\hline JQ685941.1 & SM1545 & Mephitis mephitis & United States & 2005 \\
\hline JQ685968.1 & A100512 & Mephitis mephitis & United States & 2009 \\
\hline JQ685938.1 & A100514 & Mephitis mephitis & United States & 2009 \\
\hline JQ685894.1 & CA982 & Mephitis mephitis & United States & 1994 \\
\hline JQ685970.1 & CASK2 & Mephitis mephitis & United States & 1974 \\
\hline JQ685944.1 & NC839 & Mephitis mephitis & United States & 1984 \\
\hline KC762941.1 & JX0917fb & Melogale moschata & China & 2009 \\
\hline GU647092.1 & JX0845 & Melogale moschata & China & 2008 \\
\hline FJ712195.1 & F02 & Melogale moschata & China & 2008 \\
\hline FJ712196.1 & F04 & Melogale moschata & China & 2008 \\
\hline JQ685955.1 & AZ4490 & Myotis yumanensis & United States & 2005 \\
\hline KM594032.1 & IP 497/09 & Myotis nigricans & Brazil & 2009 \\
\hline KM594031.1 & IP $163 / 10$ & Myotis nigricans & Brazil & 2010 \\
\hline KM594030.1 & IP $1400 / 10$ & Myotis nigricans & Brazil & 2010 \\
\hline KM594034.1 & IP $350 / 10$ & Nyctinomops laticaudatus & Brazil & 2010 \\
\hline KM594036.1 & IP $542 / 10$ & Nyctinomops laticaudatus & Brazil & 2010 \\
\hline KM594035.1 & IP 412/10 & Nyctinomops laticaudatus & Brazil & 2010 \\
\hline JQ685963.1 & Coati3639 & Nasua narica & Mexico & 2009 \\
\hline JQ944704.1 & $184 \mathrm{VNO}$ & Nyctereutes procyonoides & Russia & 2009 \\
\hline KC171645.1 & BV9901PJ & Nyctereutes procyonoides & South Korea & 1999 \\
\hline KC171644.1 & $\mathrm{BD} 0406 \mathrm{CC}$ & Nyctereutes procyonoides & South Korea & 2004 \\
\hline JQ685952.1 & A022971 & Parastrellus hesperus & United States & 2002 \\
\hline JQ685965.1 & A022972 & Parastrellus hesperus & United States & 2002 \\
\hline JQ685901.1 & RAC & Procyon lotor & United States & 2003 \\
\hline EU311738.1 & RRVON992 & Procyon lotor & Canada & 1999 \\
\hline JQ685922.1 & TN186 & Perimyotis subflavus & United States & 2005 \\
\hline $\mathrm{AB} 635373.1$ & H141309 & Paradoxurus zeylonensis & Sri Lanka & 2009 \\
\hline JQ685954.1 & MEXSK13938 & Spilogale putorius & Mexico & 2007 \\
\hline JQ685929.1 & MEXSK3644 & Spilogale putorius & Mexico & 2009 \\
\hline JQ685975.1 & MEXSK3636 & Spilogale putorius & Mexico & 2009 \\
\hline EU293116.1 & 9704ARG & Tadarida brasiliensis & Argentina & 1997 \\
\hline KM594038.1 & IP $1586 / 10$ & Tadarida brasiliensis & Brazil & 2010 \\
\hline KM594037.1 & IP $3176 / 09$ & Tadarida brasiliensis & Brazil & 2009 \\
\hline KM594033.1 & IP $4431 / 10$ & Tadarida brasiliensis & Brazil & 2010 \\
\hline JQ685905.1 & FL385 & Tadarida brasiliensis & United States & 2003 \\
\hline JX473841.1 & 240K09 & Tragelaphus strepsiceros & Namibia & 2009 \\
\hline JX473840.1 & 239K09 & Tragelaphus strepsiceros & Namibia & 2009 \\
\hline
\end{tabular}

Substitution rates per site per year were calculated in BEAST v 1.7.4 (Drummond et al., 2012). Before the analysis in BEAST, initial substitution rates $(\mu)$ for use as priors in the Bayesian analyses were estimated with Parth-O-Gen (http://tree.bio.ed.ac.uk/software/tempest/).

Maximum clade credibility (MCC) trees were inferred for each of the five RABV genes using a Monte Carlo Markov Chain (MCMC) approach implemented in BEAST v 1.7.4 (Drummond et al., 2012) and because RABV are under purifying selection (Troupin et al., 2016) we employed the SRD6 model (Shapiro et al., 2006) for coding sequences to avoid underestimation of TMRCA (Wertheim and Pond, 2011) with an uncorrelated relaxed molecular clock and a lognormal distribution. The previously estimated nucleotide substitution rate $(\mu)$ was used in the model.

The MCMC converged after two independent runs with 50 million generations each. Sampling was performed for every 5000 trees, which was sufficient to obtain a sample of the stationary MCMC. This was examined in Tracer v 1.5 
(http://tree.bio.ed.ac.uk/software/). An effective sample size (ESS) of greater than 200 was considered sufficient.

Estimates of nucleotide substitution rates per site per year, estimates of TMRCA for the bat-related and dog-related RABV cycles and phylogeny estimates using the concatenated $G-L$ genes

MCC trees based on the concatenated $\mathrm{G}$ and $\mathrm{L}$ genes were inferred using an MCMC approach implemented in BEAST v 1.7.4 (Drummond et al., 2012) and the SRD6 model with an uncorrelated relaxed molecular clock and a lognormal distribution (Drummond et al., 2006a). The previously estimated nucleotide substitution rate $(\mu)$ was used in the model. The MCMC converged after two independent runs with 50 million generations each. Sampling was performed for every 5000 trees. This was sufficient to obtain a sample of the stationary MCMC, which was examined in Tracer $\mathrm{v} 1.5$ (http://tree.bio.ed.ac.uk/software/). An effective sample size (ESS) of greater than 200 was considered sufficient.

\section{Results}

\section{Full-genome sequencing}

The 21 DNA samples from amplified RABV genomes were sequenced successfully; after assembly and editing they yielded DNA sequences corresponding to nucleotide 23 to nucleotide 11911 in the fixed PV strain (M13215.1), or the complete genomes without the primer hybridization regions. The sequences were deposited in GenBank under accession numbers KM594023 - KM594043.

\section{Phylogenetic signal analysis}

The results of the phylogenetic signal analysis showed that the RABV G gene is the most suitable for use in phylogenetic studies involving the bat-related and dog-related RABV cycles as it provided a better resolution than any of the four other genes or the complete genome (Table 3 ).

\section{Heterotachy analysis}

The hypothesis that the viral lineages in both RABV cycles are under the same molecular clock was less favored than the hypothesis that the lineages in each cycle are under different clocks. This finding was inferred after observing a lower likelihood value for the first model, with a significant difference between the values obtained for each model (LRT
Table 3 - Description of the phylogenetic signal found for each RABV gene and for the complete genome using the quartet method.

\begin{tabular}{lccc}
\hline Genomic region & $\begin{array}{c}\text { \% Resolved } \\
\text { quartets }\end{array}$ & $\begin{array}{c}\text { \% Unresolved } \\
\text { quartets }\end{array}$ & $\begin{array}{c}\text { \% Partially } \\
\text { resolved quartets }\end{array}$ \\
\hline N protein & 95.9 & 1.7 & 2.4 \\
P protein & 94.9 & 2.5 & 2.6 \\
M protein & 94.0 & 2.7 & 3.3 \\
G protein & 99.6 & 0.1 & 0.3 \\
L protein & 98.9 & 0.3 & 0.8 \\
Genome & 99.3 & 0.1 & 0.6 \\
\hline
\end{tabular}

$=2964.948)$, considering the critical (206.39) value in a chi-square table.

$$
\mathrm{L} 1=-246446.323 \mathrm{~L} 2=-244963.849 \mathrm{LTR}=2964 .
$$

Heterotachy was observed in RABV from bat-related and dog-related cycles. Subsequent analyses were therefore carried out separately gene by gene for each cycle in order to identify the genes responsible for this phenomenon so that the phylogenetic analyses for the bat-related and dog-related RABV cycles could be carried out together using the most suitable gene(s) for this purpose.

\section{Estimates of the nucleotide substitution rate per site per year, estimates of the TMRCA and phylogeny} estimates

This analysis was first carried out separately for all the five RABV genes for each cycle. The results are shown in Table 4.

In the dog-related cycle, the highest substitution rates were found for the $\mathrm{N}$ gene (2.26 E-4). These were approximately twice the rates for the other genes, all of which appear to be evolving at approximately similar rates with overlapping confidence intervals: P (1.17 E-4), M (1.17 E-4), G (1.18 E-4) and L (1.34 E-4). This result suggests that the constraints on nucleotide substitutions per site in the RABV N gene in the dog-related cycle are smaller than those for the $\mathrm{P}$, $\mathrm{M}, \mathrm{G}$ and $\mathrm{L}$ genes.

In the bat-related cycle the mean substitution rates for the $\mathrm{P}$ and $\mathrm{M}$ genes (2.28 E-4 and 2.49 E-4, respectively) were similar to each other but different from those for the $\mathrm{N}, \mathrm{G}$ and L genes (1.30 E-4, 1.4 E-4 and 1.15 E-4, respectively), which were also similar to each other. Unlike in the dog-related cycle, in the bat-related cycle the genes with the smallest con-

Table 4 - Nucleotide substitution rates per site and TMRCA for the N, P, M, G and L genes separately in the aerial and terrestrial cycles and for both cycles together using the $\mathrm{G}$ and $\mathrm{L}$ genes concatenated.

\begin{tabular}{|c|c|c|c|c|}
\hline \multirow[t]{2}{*}{ Gene } & \multicolumn{2}{|c|}{ Substitution rate } & \multicolumn{2}{|c|}{ TMRCA } \\
\hline & Aerial & Terrestrial & Aerial & Terrestrial \\
\hline Protein $\mathrm{N}$ & 1.30E-4 (1.22E-4 - 1.38 E-4) & $2.26 \mathrm{E}-4(1.40 \mathrm{E}-4-3.14 \mathrm{E}-4)$ & $998.524(754.16-1266.86)$ & $594.90(370.228-876.97)$ \\
\hline Protein $\mathrm{P}$ & 2.28 E-4 (2.04E-4 - 2.50E-4) & $1.17 \mathrm{E}-4$ (6.9E-5 - 1.64E-4) & $710.11(517.1-935.39)$ & $1374.14(839.82-2067.74)$ \\
\hline Protein $M$ & 2.49 E-4 (2.37E-4 -2.60E-4) & 1.17 E-4 (6.79 E-5 - 1.62 E-4) & $608.61(450.84-780.42)$ & $1100.99(639.20-1679-46)$ \\
\hline Protein G & 1.4E-4 (1.33E-4 - 1.47E-4) & 1.18 E-4 (7.19E-5 - 1.65E-4) & $1099.35(807.90-1419.75)$ & $1264.93(771.61-1844.29)$ \\
\hline Protein L & $1.15 \mathrm{E}-4(1.13 \mathrm{E}-4-1.16 \mathrm{E}-4)$ & $1.34 \mathrm{E}-4(1.32 \mathrm{E}-4-1.36 \mathrm{E}-4)$ & $1209.79(974.65-1464.61)$ & $1254.59(947.11-1622.08)$ \\
\hline $\mathrm{G}+\mathrm{L}$ & \multicolumn{2}{|c|}{$1.14 \mathrm{E}-4(7.09 \mathrm{E}-5-1.54 \mathrm{E}-4)$} & \multicolumn{2}{|c|}{$1872.16(1178-2723)$} \\
\hline
\end{tabular}


straints on nucleotide substitutions would appear to be the $\mathrm{P}$ and $\mathrm{M}$ genes.

The results for intercycle heterotachy showed that the $\mathrm{N}$ gene appears to be accumulating nucleotide substitutions in the dog-related cycle twice as fast as in the bat-related cycle (2.26 E-4 and 1.30 E-4, respectively) with non-overlap of confidence intervals. This finding indicates that the constraints on nucleotide substitutions per site in the $\mathrm{N}$ gene in RABV circulating in the bat-related cycle are greater than those in the same gene in the dog-related cycle.

The $\mathrm{P}$ and $\mathrm{M}$ genes in the bat-related cycle had higher substitution rates than in the dog-related cycle with nonoverlap of confidence intervals, indicating that the constraints on nucleotide substitutions in these genes may be greater in the dog-related cycle than in the bat-related cycle.

The L gene exhibited weaker heterotachy, and the higher rates were in the dog-related cycle (1.32 E-4 - 1.36
E-4 compared with 1.13 E-4 - 1.16 E-4 in the bat-related cycle).

Only the G gene did not exhibit any heterotachy between the cycles, suggesting that nucleotide substitution in both cycles may be subject to the same constraints.

To infer the divergence time between the lineages in the bat-related and dog-related cycles, the analysis was repeated but this time using both cycles together and only the $\mathrm{G}$ and $\mathrm{L}$ genes concatenated as these not only are evolving at approximately similar rates in both cycles (Table 3 ) but also provide the best phylogenetic signal for RABV (Table 2).

The Bayesian inference tree built with the concatenated $\mathrm{G}$ and $\mathrm{L}$ genes (Figure 1) indicated that RABV separated into bat-related and dog-related cycles around the year $230 \mathrm{CE}$. Most of the RABV lineages found in these two cycles according to the classification proposed by Bourhy et al. (2008) and Kuzmin et al. (2012), are shown in this figure.

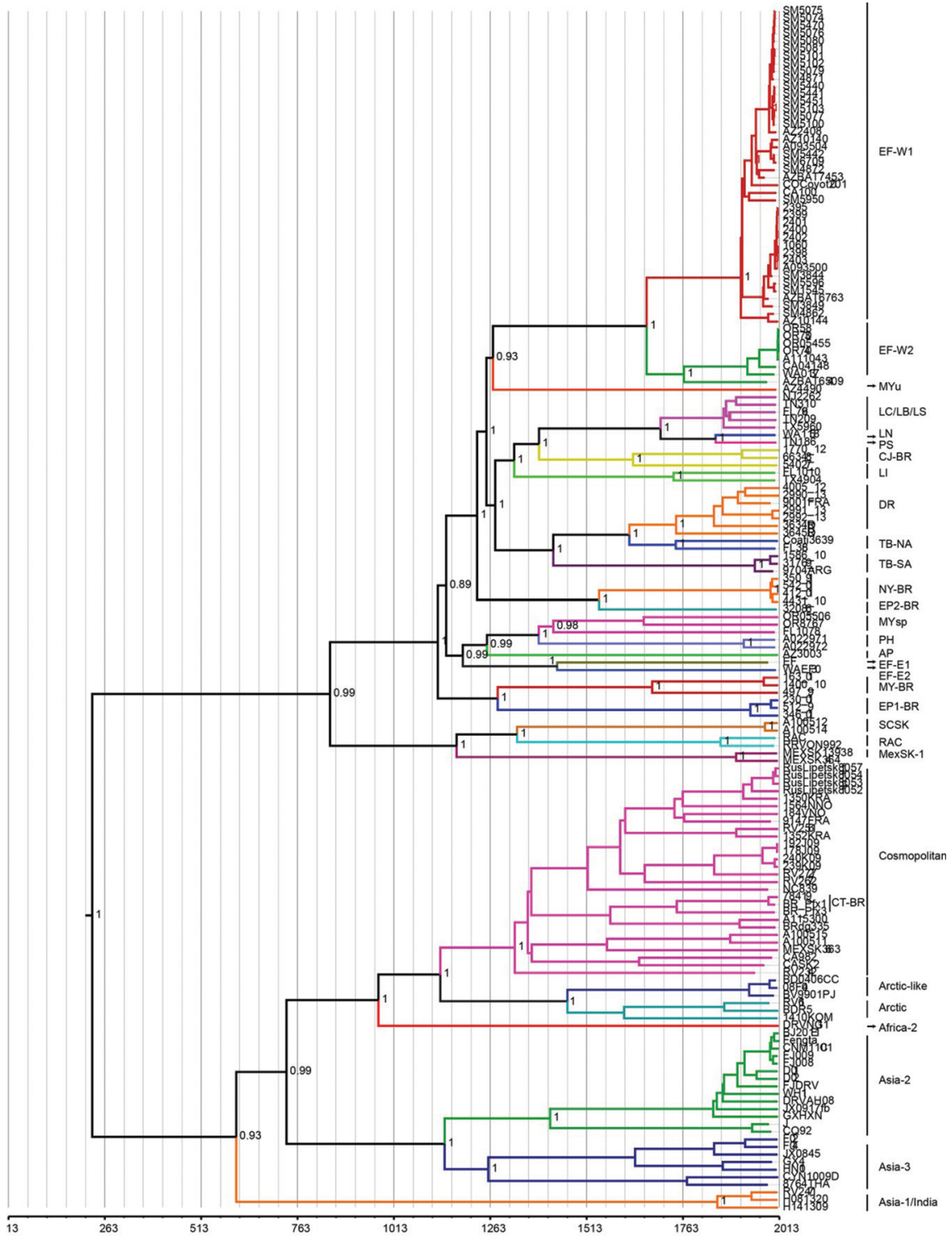

Figure 1 - Maximum clade credibility tree inferred from the concatenated G and L genes. The branches are calibrated according to the year when the lineage was isolated. The scale at the bottom of the graph is in years and can be used to identify when the separation events between RABV lineages occurred. The groups are color-coded according to the classification proposed by Bourhy et al. (2008), and Kuzmin et al. (2012). 
Also shown in the figure the Brazilian RABV lineages sequenced in this study: Myotis Brasil (MY-BR), Eptesicus 1 Brasil (EP1-BR), Eptesicus 2 Brasil (EP2-BR), D. rotundus (DR), Nyctinomops Brasil (NY-BR), T. brasiliensis South America (TB-SA), C. jacchus (CJ-BR) and C. thous (CT$\mathrm{BR})$.

\section{Discussion}

Although sequencing of complete genomes from different RABV isolates has been performed since 1986 (Tordo et al., 1986), to our knowledge DNA sequencing of complete RABV genomes using a single RT-PCR has not been described to date.

If only one amplification step is carried out to obtain the whole RABV genome sequence, the resulting sequence is more reliable as the use of different amplicons can, even if these are from the same viral sample, generate amplicons of different viral subpopulations for each of the segments being studied (Drummond et al., 2006b; Lauring et al., 2012).

As previously mentioned, in this study we investigated 25 of the 35 lineages already described for the bat-related RABV in the Americas (Favoretto et al., 2001; Drummond et al., 2006b; Oliveira et al., 2010; Streicker et al., 2010; Almeida et al., 2011; Kuzmin et al., 2012; Lauring et al., 2012), of which three (LC, LB and LS) grouped into a single monophyletic cluster. Of the eight Brazilian lineages for which virtually the complete genomes were sequenced here, the lineages Nyctinomops (NY-BR), Eptesicus Brazill (EPBR1), Eptesicus Brazil 2 (EP-BR2), Myotis Brazil (MY-BR) and C.jacchus (CJ-BR) had all their genes sequenced for the first time (Figure 1).

According to the nucleotide substitution rates found for the five RABV genes in the bat-related and dog-related cycles (Table 4), we can conclude that only the G and L genes are accumulating nucleotide substitutions at similar rates per site per year in both cycles and that these genes provide the best phylogenetic signal of all five RABV genes (Table 3). Hence, phylogenetic analyses that use nucleotide substitution rates per site per year to establish the TMRCA for RABV should not use the complete genome but only the genes that appear to be evolving at similar rates in the various lineages in the dog-related and bat-related cycles and that provide the best phylogenetic signal.

The results for the TMRCA for the bat-related and dog-related RABV cycles inferred from the concatenated $\mathrm{G}$ and $\mathrm{L}$ genes indicate that the divergence occurred around $140 \mathrm{AD}$ (Table 4). In the MCC phylogenetic tree the median value of the node corresponding to the divergence between the two cycles places this divergence in the year $230 \mathrm{AD}$ (Figure 1). Differences of this nature are inherent to Bayesian inferences (Drummond et al., 2005, 2012).

Using 151 sequences from the complete $\mathrm{N}$ gene $(25 \mathrm{se}-$ quences from the bat-related cycle and 126 from the dogrelated cycle) Bourhy et al. (2008) inferred that the two cycles separated around $1250 \mathrm{AD}$. In the same study, when they used 74 sequences from the complete $\mathrm{G}$ gene ( 2 from the bat-related cycle and 72 from the dog-related cycle), authors dated this divergence to $1400 \mathrm{AD}$.

Nevertheless, our results show that although it is the most conserved of the RABV genes, the $\mathrm{N}$ gene neither provides the best phylogenetic signal nor has similar nucleotide substitution rates per site per year in both cycles and is therefore not the ideal gene for estimating the TMRCA. This, together with the small number of bat-related lineages and sequences studied by Bourhy et al. (2008) in the bat-related cycle, particularly in the case of the G gene, is the likely cause of the differences in the results for the TMRCA in the two cycles between this study and the study by Bourhy et al., 2008.

Based on the MCC tree built using concatenated G and $\mathrm{L}$ genes, the median node dates corresponding to the origin of each cycle are approximately $850 \mathrm{AD}$ for the bat-related cycle (a posterior of 0.99 ) and $600 \mathrm{AD}$ for the dog-related cycle (a posterior of 0.93 ). This would indicate that the representatives of RABV in the dog-related cycle are older and have been evolving for longer than those of RABV in the bat-related cycle, although the confidence intervals overlap, which is expected as the lineages in each cycle diverged at about the same time. One of the hypotheses for this difference in the data of origin of each cycle is the representativeness of the RABV sequences used in the analysis, as these may not include the oldest lineages in each cycle.

All the existing RABV lineages maintained in the dog-related cycle shared a common ancestor with the Asia 1/India domestic-dog lineage around $600 \mathrm{AD}$. Asia 1/India occupies the most basal position in this group, suggesting that this lineage, which circulates in southern India, was the first to diverge and thus the oldest circulating in the dog-related cycle. This would corroborate the findings reported by Bourhy et al. (2008).

Troupin et al. (2016), using the five concatenated RABV genes and dog-related lineages, estimated this divergence to have occurred between the years 1308 and 1510 $\mathrm{AD}$. This variation lies within the confidence intervals of the estimates calculated here using the concatenated bat-related and dog-related RABV G and $\mathrm{L}$ genes as well as each of the five RABV genes when the TMRCA using only dog-related RABV was assessed (Table 4). The discrepancy regarding the mean values is probably because Troupin et al. (2016) did not include bat-related RABV strains in their analysis and therefore did not take into account the common origin of bat- and dog-related RABV.

Similarly, Velasco-Villa et al. (2017), using the N gene, estimated that dog-related RABV diverged between 1273 and $1562 \mathrm{AD}$, a result also found in the present study using all genes separately and lineages from the dog-related cycle (Table 4), as bat-related RABV lineages were not used in the study by Velasco-Villa et al. (2017).

The Cosmopolitan complex of lineages, which includes those maintained in canids in Brazil, was estimated to have originated around $1300 \mathrm{AD}$. The basal group in this complex is a sample isolated in the 1950s in a dog in Israel (RV2324 - KF154998.1). In their study of the phylogeo- 
graphy of canine rabies around the world, Bourhy et al. (2008) found that the basal group for the Cosmopolitan complex was a sample isolated in a human in the 1970s in Egypt (8692EGY - U22627), which is genetically very similar to the RV2324 isolate.

The isolate from Egypt shares an ancestor with the other lineages in the Cosmopolitan complex, which includes the lineage maintained by wild canids in South America, lineages maintained by the striped skunk and wild canids in North America and some lineages maintained by wild canids in Eurasia and dogs in Africa (Kuzmin et al., 2012).

The lineages maintained in Brazil in independent epidemiologic cycles by the crab-eating fox (Cerdocyon thous) (CT-BR lineage) and domestic dog (Domestic dog-BR) apparently shared a common ancestor and have evolved independently in each of these reservoirs since approximately $1570 \mathrm{AD}$, corroborating the hypothesis that rabies in wild canids in the Americas is associated with European colonization of the continent from the $14^{\text {th }}$ century onwards (Baer, 2007).

As already shown by other authors (Bourhy et al., 2008; Kuzmin et al., 2012), in the MCC phylogenetic tree inferred from the concatenated $\mathrm{G}$ and $\mathrm{L}$ genes (Figure 1), the MexSK-1, SCSK and RAC lineages, which are maintained in the eastern spotted skunk (Spilogale putorius), the striped skunk (Mephitis mephitis) and the raccoon (Procyon lotor), respectively, share a common ancestor with all the other lineages in the bat-related cycle maintained by bats and the common marmoset (C. jacchus). The divergence between these two groups occurred around $850 \mathrm{AD}$. Although the reservoir of this ancestral RABV remains unknown, some authors have put forward the hypothesis that this original reservoir of the rabies virus in the Americas was a chiropteran (Badrane and Tordo, 2001; Hayman et al., 2016; Velasco-Villa et al., 2017).

In the bat-related cycle, the common ancestor of the complex of lineages maintained in North American carnivores and its diversification into the current lineages was dated in the present study to approximately $1170 \mathrm{AD}$, while the common ancestor of RABV maintained in chiropterans and its diversification into the many existing lineages was inferred to around 1110 AD. For both estimates, the confidence intervals overlapped.

Among the lineages in the bat-related cycle maintained by bats and C.jacchus, the most basal group consists of two Brazilian lineages, Myotis Brazil (MY-BR) and Eptesicus Brazil 1 (EP1-BR), which shared a common ancestor in around $1280 \mathrm{AD}$ (Figure 1). However, this result should be interpreted with caution, as this basal position was not confirmed in ML analyses performed with the complete genome (Kotait et al., 2019), and many lineages in this cycle were not included in the present study.

The Brazilian lineage C. jacchus (CJ-BR), the only RABV lineage which has a primate as its reservoir (Kotait et al., 2019), was estimated here to have originated around $1600 \mathrm{AD}$. It shared an ancestor around $1400 \mathrm{AD}$ with RABV lineages maintained by different species of bats in the genus
Lasiurus (LB, LC, LS) and the species Lasionycteris noctivagans (LN) and Perimyotis subflavus (PS) in North America (Figure 1). The fact that the LC lineage also circulates in bats in the genus Lasiurus in Brazil (Oliveira et al., 2010) makes this common origin quite plausible.

Although the lineages Nyctinomops Brazil (NY-BR) and Eptesicus Brazil 2 (EP2-BR) have already been described by other authors (Kobayashi et al., 2005, 2007a,b; Baer, 2007; Oliveira et al., 2010; Albas et al., 2011; Almeida et al., 2011), their probable divergence from a common ancestor around $1550 \mathrm{AD}$ has not been reported in the literature to date.

The close relationship between the lineages T. brasiliensis North America (TB-NA) and D. rotundus (DR) is already known, and our findings suggest that the divergence between the two lineages occurred around 1600 AD. As suggested in other studies, the T. brasiliensis South America (TB-SA) lineage is probably the basal group for the $T$. brasiliensis North America and D. rotundus lineages (Kobayashi et al., 2005; Oliveira et al., 2010; Kuzmin et al., 2012), and the divergence from the common ancestor that gave rise to the TB-NA and DR lineages probably occurred around $1400 \mathrm{AD}$.

While the geographic distribution of the RABV lineages can be clearly seen in the dog-related cycle (showing the migration from India to Eurasia and Africa and finally the Americas as a result of the great maritime expeditions in the $15^{\text {th }}$ century), the geographic isolation is not so readily apparent in the lineages in the bat-related cycle. The clustering of the lineages in this cycle is primarily a result of the specific nature of the reservoirs, although certain populations in some lineages in this cycle have a geographic distribution (Streicker et al., 2010, 2012a,b). Nevertheless, L. cinereus has already been isolated in bats of the genus Lasiurus in North America and Brazil, showing that this lineage circulates between continents (Oliveira et al., 2010; Streicker et al., 2010; Kuzmin et al., 2012; Svitek et al., 2014).

Given the representativeness of the data used in this study, we can consider there to be five host genera (Canis, Vulpes, Nyctereutes, Mephitis and Cynictis) acting in the selective processes involved in the adaptation and selection of representative lineages in the dog-related cycle and at least thirteen (Mephitis, Procyon, Callithrix, Myotis, Eptesicus, Lasiurus, Nyctinomops, Tadarida, Perimyotis, Lasionycteris, Desmodus, Parastrellus and Antrozous) acting in the bat-related cycle. In the latter cycle, species-specific lineages can be found in certain genera (Favoretto et al., 2001; Oliveira et al., 2010; Streicker et al., 2010; Kuzmin et al., 2012).

Like the vast majority of RNA viruses, the RABV RNA-dependent RNA polymerase complex formed by the $\mathrm{P}$ and $\mathrm{L}$ proteins does not have any proofreading 3' to 5' exonuclease activity. This, together with the large number of progeny and the short interval between RABV life cycles, leads to a high mutation rate with a high probability of neutral mutations getting fixed in mutant subpopulations that 
maintain themselves by replicating at a lower frequency than the original (master) population in their reservoirs. When this complex composite viral population faced sudden habitat change as a result of, for example, interspecific transmission events, these heterogeneous viral populations may have been responsible for improved adaptability in a new host, leading to intraspecific transmission and the emergence of new RABV lineages or a newly dominant consensus (Streicker et al., 2010, 2012a; Lauring et al., 2012; Borucki et al., 2013).

Different evolutionary patterns resulting from adaptation and evolution in different reservoirs can be reflected in a variety of nucleotide substitution rates in a given site and year for the same gene in RABV distributed between the bat-related and dog-related RABV. Such evolutionary patterns can also lead to differences in the number of sites under selection in these genes as well as to differences in the selection regime acting in these (Lopez et al., 2002).

Each species of RABV reservoir can be considered a specific habitat in which each viral lineage adapts and evolves, and the variety of reservoirs currently found for RABV can be considered different adaptive landscapes (Wright 1932) in which different viral populations can adapt in different ways. Sympatric reservoirs for different species can be considered isolated environments that differ from each other in terms of the viruses for which they are reservoirs even though they occupy the same habitat (Wasik and Turner, 2013).

The separation of RABV into bat-related and dogrelated inferred to have occurred around $200 \mathrm{AD}$ according to the results presented here helped shape specific genetic and phenotypic characteristics and patterns for the viruses in each of these cycles. Nevertheless, this is not taken into account in classifications and descriptions of the epidemiologic cycles of rabies, which are today divided into an urban and a sylvatic cycle (Acha and Szyfres, 2003). Instead, only factors related to reservoirs and the environment are considered, while factors inherent to the etiologic agent are overlooked.

\section{Acknowledgments}

This study was supported by Health State Secretary of São Paulo. Thanks are also due to CNPq (grant\#307291/2017-0).

\section{Conflict of Interest}

The authors have no conflict of interest to declare.

\section{Author Contributions}

All authors contributed to the study conception and design. The study was conceived by RNO, AI, CCF, PEB and $\mathrm{PMZ}$. Material preparation, data collection and analysis were performed by RNO, CCF, AI, RP, SSS, JGC, HBCRB, CIM and JTW. The first draft of the manuscript was written by RNO, PEB, CCF, AI, SSS and PMZ. The manuscript was reviewed and edited by RNO, PEB, SPS, CCF and PCJr. and all authors commented on previous versions of the manuscript. All authors read and approved the final manuscript.

\section{References}

Acha PN and Szyfres B (2003) Zoonoses y enfermeddes transmisibles comunes al hombre y a los animales. 3nd edition. Organization Panamericana de la Salud, Washington, vol. 2.

Albas A, Campos AC de A, Araujo DB, Rodrigues CS, Sodré MM, Durigon EL and Favoretto SR (2011) Molecular characterization of rabies virus isolated from non-haematophagous bats in Brazil. Rev Soc Bras Med Trop 44:678-83.

Almeida MF De, Favoretto SR, Martorelli LFA, Trezza-Netto J, Campos ACDA, Ozahata CH, Sodré MM, Kataoka APAG, Sacramento DRV and Durigon EL (2011) Characterization of rabies virus isolated from a colony of Eptesicus furinalis bats in Brazil. Rev Inst Med Trop Sao Paulo 53:31-37.

Badrane H and Tordo N (2001) Host switching in Lyssavirus history from the Chiroptera to the Carnivora orders. J Virol 75:8096-8104.

Baer GM (2007) The History of Rabies. In: Jackson AC and Wunner WH (eds) Rabies. 2nd edition. San Diego, pp 1-21.

Bazinet AL, Zwickl DJ and Cummings MP (2014) A gateway for phylogenetic analysis powered by grid computing featuring GARLI 2.0. Syst Biol 63:812-818.

Bourhy H, Reynes JM, Dunham EJ, Dacheux L, Larrous F, Huong VTQ, Xu G, Yan J, Miranda MEG and Holmes EC (2008) The origin and phylogeography of dog rabies virus. J Gen Virol 89:2673-2681.

Campos ACDA, Melo FL, Romano CM, Araujo DB, Cunha EMS, Sacramento DRV, de Andrade Zanotto PM, Durigon EL and Favoretto SR (2011) One-step protocol for amplification of near full-length cDNA of the rabies virus genome. J Virol Methods 174:1-6.

Carnieli P, Fahl WDO, Castilho JG, Oliveira RDN, Macedo CI, Durymanova E, Jorge RSP, Morato RG, Spíndola RO, Machado LM et al. (2008) Characterization of Rabies virus isolated from canids and identification of the main wild canid host in Northeastern Brazil. Virus Res 131:33-46.

Drummond AJ, Rambaut A, Shapiro B and Pybus OG (2005) Bayesian coalescent inference of past population dynamics from molecular sequences. Mol Biol Evol 22:1185-1192.

Drummond AJ, Ho SYW, Phillips MJ and Rambaut A (2006a) Relaxed phylogenetics and dating with confidence. PLoS Biol 4:e88.

Drummond AJ, Ho SYW, Phillips MJ and Rambaut A (2006b) Relaxed phylogenetics and dating with confidence. PLoS Biol 4:e88.

Drummond AJ, Suchard MA, Xie D and Rambaut A (2012) Bayesian phylogenetics with BEAUti and the BEAST 1.7. Mol Biol Evol 29:1969-1973.

Favoretto SR, de Mattos CC, Morais NB, Alves Araújo FA and de Mattos CA (2001) Rabies in marmosets (Callithrix jacchus), Ceará, Brazil. Emerg Infect Dis 7:1062-1065.

Hayman DTS, Fooks AR, Marston DA and Garcia RJC (2016) The Global Phylogeography of Lyssaviruses - Challenging the "Out of Africa" Hypothesis. PLoS Negl Trop Dis 10:e005266.

Hu SC, Hsu CL, Lee MS, Tu YC, Chang JC, Wu CH, Lee SH, Ting LJ, Tsai KR, Cheng MC et al. (2018) Lyssavirus in Japanese pipistrelle, Taiwan. Emerg Infect Dis 24:782-785.

King AMK, Adans MJ, Carstens EB and Lefkowitz EJ (2012) Genus Lyssavirus. In: King AMQ, Adams MJ, Carstens EB and 
Lefkowitz EJ (eds) International Committee on Taxonomy of Viruses. 9th edition. Elsevier, San Diego, pp 696-699.

Kobayashi Y, Inoue N, Sato G, Itou T, Santos HP, Brito CJC, Gomes AAB, Santos MFC, Silva MV, Mota CS et al. (2007a) Phylogenetic characterization of rabies virus isolates from Carnivora in Brazil. J Vet Med Sci 69:691-696.

Kobayashi Y, Sato G, Kato M, Itou T, Cunha EMS, Silva MV, Mota CS, Ito FH and Sakai T (2007b) Genetic diversity of bat rabies viruses in Brazil. Arch Virol 152:1995-2004.

Kobayashi Y, Sato G, Shoji Y, Sato T, Itou T, Cunha EMS, Samara SI, Carvalho AAB, Nociti DP, Ito FH et al. (2005) Molecular epidemiological analysis of bat rabies viruses in Brazil. J Vet Med Sci 67:647-652.

Koprowski H (1996) The mouse inoculation test. In: Meslin FX, Kaplan MM and Koprowski H (eds) Laboratory techniques in rabies, 4th edition. World Health Organization, Geneva, pp 80-86.

Kotait I, Oliveira RN, Carrieri ML, Castilho JG, Macedo CI, Pereira PMC, Boere V, Montebello L and Rupprecht CE (2019) Non-human primates as a reservoir for rabies virus in Brazil. Zoonoses Public Health 66:47-59.

Kuzmin IV and Rupprecht CE (2007) Bat rabies. In: Jackson A and Wunner WH (eds) Rabies, 2nd edition. Academic Press, San Diego, pp 259-307.

Kuzmin IV, Shi M, Orciari LA, Yager PA, Velasco-Villa A, Kuzmina NA, Streicker DG, Bergman DL and Rupprecht CE (2012) Molecular inferences suggest multiple host shifts of rabies viruses from bats to mesocarnivores in Arizona during 2001-2009. PLoS Pathog 8:e1002786.

Lauring AS, Acevedo A, Cooper SB and Andino R (2012) Codon usage determines the mutational robustness, evolutionary capacity, and virulence of an RNA virus. Cell Host Microbe 12:623-632.

Lopez P, Casane D and Philippe H (2002) Heterotachy, an important process of protein evolution. Mol Biol Evol 19:1-7.

Marston DA, Horton DL, Ngeleja C, Hampson K, Mc Elhinney LM, Banyard AC, Haydon D, Cleaveland S, Rupprecht CE, Bigambo $\mathrm{M}$ et al. (2012) Ikoma lyssavirus, highly divergent novel lyssavirus in an African civet. Emerg Infect Dis 18:664-667.

Martin DP, Lemey P, Lott M, Moulton V, Posada D and Lefeuvre P (2010) RDP3: A flexible and fast computer program for analyzing recombination. Bioinformatics 26:2462-2463.

Mollentze N, Biek R and Streicker DG (2014) The role of viral evolution in rabies host shifts and emergence. Curr Opin Virol $8 \mathrm{C}: 68-72$.

Oliveira RN (2014) Modos e tempo de evolução em linhagens do vírus da raiva (RABV) mantidos por reservatórios aéreos e terrestres com base em genomas completos. D. Sc. Thesis, Faculdade de Medicina Veterinária e Zootecnia, Universidade de São Paulo, São Paulo, 25 p.

Oliveira RDN, de Souza SP, Lobo RSV, Castilho JG, Macedo CI, Carnieli P, Fahl WO, Achkar SM, Scheffer KC, Kotait I et al. (2010) Rabies virus in insectivorous bats: Implications of the diversity of the nucleoprotein and glycoprotein genes for molecular epidemiology. Virology 405:352-360.
Rupprecht C, Kuzmin I and Meslin F (2017) Lyssaviruses and rabies: Current conundrums, concerns, contradictions and controversies. F1000Res 6:184.

Rupprecht CE, Hanlon CA and Hemachudha T (2002) Rabies re-examined. Lancet Infect Dis 2:327-343.

Schmidt HA, Strimmer K, Vingron M and von Haeseler A (2002) TREE-PUZZLE: maximum likelihood phylogenetic analysis using quartets and parallel computing. Bioinformatics 18:502-504.

Shapiro B, Rambaut A and Drummond AJ (2006) Choosing appropriate substitution models for the phylogenetic analysis of protein-coding sequences. Mol Biol Evol 23:7-9.

Streicker DG, Altizer SM, Velasco-Villa A and Rupprecht CE (2012a) Variable evolutionary routes to host establishment across repeated rabies virus host shifts among bats. Proc Natl Acad Sci U S A 109:19715-19720.

Streicker DG, Lemey P, Velasco-Villa A and Rupprecht CE (2012b) Rates of viral evolution are linked to host geography in bat rabies. PLoS Pathog 8:e1002720.

Streicker DG, Turmelle AS, Vonhof MJ, Kuzmin IV, McCracken GF and Rupprecht CE (2010) Host phylogeny constrains cross-species emergence and establishment of rabies virus in bats. Science 329:676-679.

Strimmer K and von Haeseler A (1997) Likelihood-mapping: a simple method to visualize phylogenetic content of a sequence alignment. Proc Natl Acad Sci U S A 94:6815-6819.

Svitek N, Gerhauser I, Goncalves C, Grabski E, Döring M, Kalinke U, Anderson DE, Cattaneo R and von Messling V (2014) Morbillivirus control of the interferon response: relevance of STAT2 and mda5 but not STAT1 for canine distemper virus virulence in ferrets. J Virol 88:2941-2950.

Tordo N, Poch O, Ermine A, Keith G and Rougeon F (1986) Walking along the rabies genome: Is the large G-L intergenic region a remnant gene? Proc Natl Acad Sci U S A 83:3914-3918.

Troupin C, Dacheux L, Tanguy M, Sabeta C, Blanc H, Bouchier C, Vignuzzi M, Duchene S, Holmes EC and Bourhy H (2016) Large-scale phylogenomic analysis reveals the complex evolutionary history of rabies virus in multiple carnivore hoss. PLoS Pathog 12:e1006041.

Velasco-Villa A, Mauldin MR, Shi M, Escobar LE, GallardoRomero NF, Damon I, Olson VA, Streicker DG and Emerson G (2017) The history of rabies in the Western Hemisphere. Antiviral Res 146:221-232.

Wasik BR and Turner PE (2013) On the biological success of viruses. Annu Rev Microbiol 67:519-541.

Wertheim JO and Kosakovsky Pond SL (2011) Purifying selection can obscure the ancient age of viral lineages. Mol Biol Evol 28:3355-3365.

Wright S (1932) The roles of mutation, inbreeding, crossbreeding and selection in evolution. In: Proceedings of the Sixth International Congress on Genetics, New York, vol. 1.

Yang Z (2007) PAML 4: Phylogenetic analysis by maximum likelihood. Mol Biol Evol 24:1586-1591.

Associate Editor: Bertram Brenig

License information: This is an open-access article distributed under the terms of the Creative Commons Attribution License (type CC-BY), which permits unrestricted use, distribution and reproduction in any medium, provided the original article is properly cited. 